\title{
Sustentabilidad en el área turística Estero San José del Cabo, México
}

\author{
Elizabeth Olmos-Martínez*, Reyna lbáñez Pérez ${ }^{\star \star}$ y Juan Pedro lbarra-Michel ${ }^{\star \star *}$
}

\begin{abstract}
RESUMEN
La Reserva Ecológica Estatal Estero de San José del Cabo (REeESJC) es un área natural protegida (ANP) en el municipio de Los Cabos, un destino turístico importante de México. El objetivo de esta INVESTIGACIÓN ES ANALIZAR LA PERCEPCIÓN Y OPINIÓN DE LAS AUTORIDADES QUE ADMINISTRAN EL ÁREA, ASÍ COMO LOS GRUPOS DE INTERÉS (LÍDERES COMUNITARIOS Y EMPRESARIOS) SOBRE LA SUSTENTABILIDAD DEL ANP. DURANTE 2016 SE APLICÓ UNA ENCUESTA CON VARIABLES CUALITATIVAS Y CUANTITATIVAS. LOS ENCUESTADOS PERCIBEN COMO PRINCIPAL

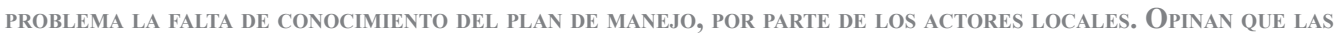
ESTRATEGIAS PRIORITARIAS DE MANEJO DEBEN SER LA CONSERVACIÓN Y VIGILANCIA. LAS AUTORIDADES Y GRUPOS DE INTERÉS QUE SE ENCARGAN DE LA PLANEACIÓN DE LAS ACTIVIDADES TURíSTICAS EN EL ÁREA DE ESTUDIO MUESTRAN UN DESCONOCIMIENTO SISTEMÁTICO DE INFORMACIÓN QUE LES PERMITIRÍA PROPONER ACCIONES DE CONSERVACIÓN EFICACES FRENTE AL RETO DE LA SUSTENTABILIDAD DEL ANP.
\end{abstract}

Palabras Clave: sustentabilidad - CONSERvación - Área natural protegida - Percepción - turismo - Reserva Ecológica Estero de San José del Cabo, México.

\section{Sustainability in the Touristic Area of Estero San José del Cabo, Mexico}

\section{Abstract}

The San José del Cabo State Estuary Ecological Reserve (REeESJC) is a protected natural area (ANP) in the municipality of Los Cabos, a major tourist destination in Mexico. The objective of this research is TO ANALYZE THE PERCEPTION AND OPINION OF MANAGING AUTHORITIES AND INTEREST GROUPS (COMMUNITY LEADERS AND ENTREPRENEURS) ON THE SUSTAINABILITY OF THE ANP. DURING 2016, A SURVEY WAS APPLIED WITH QUALITATIVE AND QUANTITATIVE VARIABLES. RESPONDENTS PERCEIVE LOCAL ACTORS' LACK OF KNOWLEDGE OF THE MANAGEMENT PLAN AS A MAIN PROBLEM. THEY BELIEVE THAT THE PRIORITY MANAGEMENT STRATEGIES SHOULD BE THOSE OF CONSERVATION AND SURVEILLANCE. THE AUTHORITIES AND INTEREST GROUPS THAT ARE RESPONSIBLE FOR THE PLANNING OF TOURISM ACTIVITIES IN THE STUDY AREA SHOW A SYSTEMATIC IGNORANCE OF INFORMATION THAT WOULD ALLOW THEM TO PROPOSE EFFECTIVE CONSERVATION ACTIONS IN THE FACE OF CHALLENGES TO THE SUSTAINABILITY OF THE ANP.

KEYWORDS: SUSTAINABILITY - CONSERVATION - PROTECTED NATURAL AREA - PERCEPTIONS - TOURISM - RESERVA Ecológica Estero de San José del Cabo, Mexico.

* Universidad Autónoma de Occidente. Doctora en Ciencias en Uso, Manejo y Preservación de los Recursos Naturales. Distinguida por el Sistema Nacional de Investigadores nivel I. Sus líneas de investigación son: turismo, áreas naturales protegidas, desarrollo sustentable y cambio climático. Autor corresponsal. Correo electrónico: eolmosm.udo@gmail.com.

* Universidad Autónoma de Baja California Sur. Doctora En Ciencias por la Universidad Autónoma de Baja California Sur donde colabora como Profesora Investigadora. Miembro de la Academia Mexicana de Investigación Turística y del Sistema Nacional de Investigadores de México. Correo electrónico: ribanez@uabcs.mx.

*** Universidad Autónoma de Occidente. Licenciado en Administración Turística, Maestría en Desarrollo Estratégico del Turismo, Doctorado en Ciencias Administrativas. Investigador y autor de artículos científicos publicados en revistas internacionales en Europa y Latinoamérica. Experiencia en administración, gestión del turismo y sustentabilidad. Correo electrónico: juanpedroibarra.udo@gmail.com. 


\section{Introducción}

T a sustentabilidad es, según Daly y Gayo (1995: 21), un proceso donde interactúan entre sí tres sistemas y/o dimensiones: el ecológico, el económico y el social. Por otro lado, se han desarrollado diversas posturas con relación a la importancia y posibilidad de remplazar algunas de sus dimensiones (Barbier et al., 1990; Common y Perrings, 1992: 7). Por ejemplo, la llamada sustentabilidad fuerte afirma que el capital natural debe ser sostenido (Naredo, 1992; Bergh y Hofkes, 1997); mientras que el enfoque de sustentabilidad débil prioriza el bienestar económico y argumenta que una pérdida del capital natural puede ser sustituido mediante la creación de capital tecnológico (Jamieson, 1998; Solow, 1993; Pearce y Atkinson, 1995, Hanley et al., 1997). Independientemente de las limitaciones o aciertos de los conceptos expuestos, en el fondo la sustentabilidad no es un ajuste tecnológico ni un asunto de nuevas inversiones financieras; más bien se refiere a un cambio de valores y forma de pensar (Turner, 1993) que lleven a que se tomen en cuenta las relaciones entre la economía, el medio ambiente y la sociedad, así como la participación de la sociedad y la interdisciplinaridad en el diseño de políticas o modelos.

Lo anterior, ha generado medidas en la escala mundial, reflejados en la implementación de una serie de estrategias, programas y acuerdos que enfatizan en la necesidad de conservar lugares con alta riqueza natural, pero son mayormente vulnerables por las actividades que involucran la interacción del hombre y la naturaleza, o simplemente por ser aprovechadas con fines económicos y recreativos a través de actividades como el turismo. También enfatizan zonas que por su naturaleza resultan más vulnerables en términos socio ambientales que otras (Ibáñez, 2014).

Tal acción, ha influido en un cambio en las tendencias de la demanda y que, se caracterizan por el creciente interés de los visitantes por disfrutar de actividades recreativas en espacios naturales muy bien conservados (Tudela y Giménez, 2008). Llevado a que, naciones biodiversas como México, fortalezcan sus acciones en pro del aprovechamiento del potencial de áreas con tales características (Fasio e Ibáñez, 2011). Lo anterior, sumado a su mega diversidad ha contribuido a que el turismo represente una de las principales fuentes de ingreso para el país, que recibirá en el año 2020 un estimado de 48.9 millones de visitantes, de los cuales buena parte buscaran zonas con alta presencia de atractivos naturales y calidad ambiental lo anterior, propiciado por un aumento de la demanda de servicios de recreación en Áreas Naturales Protegidas (ANP) donde según señalan Arizpe et al., (2017) tan solo entre el año 2002 al 2005, el número de visitantes de las ANP alcanzó los 20 millones, generando una derrama económica de aproximadamente \$ 5 mil millones de pesos (Comisión Nacional de Áreas Naturales Protegidas [CONANP], 2006). Actualmente, se considera que 89 de las 181 ANP de México, cuentan con potencial para realizar actividades relacionadas con el turismo sustentable y de acuerdo con el registro de visitación y conforme al cobro de derechos de la CONANP (2016), el mayor flujo turístico se registró en 2015.

Para el caso específico de Baja California Sur (BCS), las ANP donde se presenta una importante afluencia de visitantes son el Parque Nacional de Cabo Pulmo, Área de Protección de Flora y Fauna Cabo San Lucas, el Área de Protección de Flora y Fauna Islas del Golfo de California y la Reserva Ecológica Estatal Estero de San José del Cabo esta última, constituye la zona de estudio en esta investigación.

Por otro lado, cabe destacar que, a la fecha, no existen estadísticas globales, sobre el número de visitantes en todas las ANP de BCS; sin embargo, con base a datos de Ibáñez (2016), Cortes y Miranda (2015), Hernández (2013), Calderón et al., (2013), Fasio (2013), Rebolledo (2013) y la Secretaría del Medio Ambiente y Recursos Naturales (SEMARNAT, 2013), se estima que en 2011 se recibieron 155,557 personas quienes realizaron actividades turísticas-recreativas. Asimismo, la derrama económica tan solo por pago de derechos osciló en $\$ 9,333,420$ pesos esto sin considerar gastos de traslado, hospedaje, alimentación, transportación local y contratación de servicios recreativos (Ibáñez, 2014; 2016). 
En ese sentido, las ANP se encuentran entre los sistemas más frágiles y fuertemente presionados por la actividad humana (Cervantes-Martínez, et al., 2013), entre ellas por la actividad turística en las modalidades de ecoturismo, turismo de naturaleza, turismo rural, etc., lo que hace indispensable analizarlas para con ello proponer estrategias de manejo que permitan reducir los riesgos a factores antropogénicos y fenómenos naturales, para lograr conservar la integridad de los ecosistemas y su biodiversidad.

La estrategia de creación y manejo de las ANP se ha convertido en elemento clave en la conservación de nuestro entorno (Olmos-Martínez, et al., 2013a). En el municipio de Los Cabos, BCS destaca la Reserva Ecológica Estatal Estero San José del Cabo (REEESJC) por su importancia ambiental, económica, social y cultural (CONANP-SEMARNAT, 2000). La actividad antrópica de la ciudad de San José del Cabo (SJC) y zona sureste del estero (Zona cercana a la población La Playa y la marina) limita con áreas naturales del estero donde se observa zonas de transformación drásticas en el uso de suelo para urbanización, algunas de las cuales por su condición física (planicie aluvial) no permitirían el desarrollo urbano (Armenta, 2015).

Finamente, se sabe que los retos de la sostenibilidad pasan por aspectos sociales, políticos, económicos, tecnológicos y educativos, que llevarán a desafiar cualquier programa a ir más allá de unas acciones puntuales para alcanzarla. Entonces la función regulatoria de las instituciones depende de la construcción discursiva de los problemas (González, et al., 2017). No es la crisis física del medio ambiente lo que provoca el cambio social, tampoco la destrucción de ciertos bienes socialmente valorados, sino la creación de imágenes y problemas identificables que permiten a la gente posiciones y perspectivas diferentes, compartir una imagen común de lo que puede ser considerado un problema (Lezama, 2008; González, et al., 2017).

Por lo anterior el objetivo de esta investigación fue conocer la percepción y conocimiento de las autoridades (municipales, estatales y federales), empresarios, grupos sociales y organizaciones de la sociedad civil que comparten intereses relacionados con el manejo y conservación de la REEESJC y que desarrollan sus actividades (económicas -entre ellas la planeación de las actividades turísticas-, de conservación y manejo) dentro de la zona de influencia del estero (500 metros de la línea poligonal del área) con la finalidad de contar con información que sirva de herramienta para la toma de decisiones en la búsqueda del desarrollo turístico local sustentable a partir del análisis de los temas de sustentabilidad, conservación y uso de los recursos naturales, así como de las amenazas ambientales.

\section{Turismo y áreas naturales protegidas}

El ocio y las vacaciones se han convertido para la economía capitalista y neoclásica en un producto demandado, para satisfacerla, la oferta crea destinos turísticos principalmente en la costa, los cuales se sitúan en la periferia de los principales centros urbanos e industriales del mundo (Clavé, 1998). Para estos espacios su suelo se convierte en una mercancía, la aparición de nuevos usos de suelo, las estructuras territoriales preexistentes adquieren nueva forma y la metamorfosis de la base productiva regional y local (Ibáñez, 2014).

Se sabe que las actividades de ecoturismo en ausencia de procesos efectivos de planeación y administración de la actividad pueden ocasionar impactos en los recursos naturales como por ejemplo en la vegetación, suelo, agua y fauna, o impactos sociales como conflictos entre prestadores de servicios por el uso de los recursos y la aglomeración de los visitantes (Bojórquez, 2002; Cervantes, 2012, Olmos-Martínez, 2015) por lo que la estrategia de creación, consolidación y manejo de las ANP se ha convertido en elemento clave en la conservación de nuestro entorno (SAGARPA - Gob. BCS, 2011).

En ese sentido, las ANP son instrumentos estratégicos; es en estas áreas donde se conservan distintos recursos naturales y se convierten en fuentes generadoras de múltiples beneficios socioeconómicos y culturales (Mulongoy y Chape, 2004). Su importancia radica en que mantienen hábitats clave, proveen de refugio, permiten la migración y movimientos de las especies, aseguran 
el mantenimiento de los procesos naturales, son la principal fuente de agua potable para más de la tercera parte de las ciudades más grandes del mundo y, son de gran importancia en cuanto a la seguridad alimenticia del planeta (Kettunen et al., 2010). Asimismo, la creciente sensibilidad medio-ambiental de la sociedad se plasma en la creación de organizaciones políticas nacionales e internacionales cuyos programas abanderan, al menos nominalmente, la preservación del medio (Novo, 2002).

La creciente visitación turístico-recreativa a las ANP es una realidad mundial. A partir de esta tendencia, el estudio, discusión e investigación del fenómeno turístico y recreativo en dichas áreas ha ido acrecentándose también en foros y organismos internacionales (SEMARNAT-CONANP, 2014). Esta clase de turismo ha sido reconocido en diversas convenciones y declaraciones como una oportunidad de desarrollo sustentable. Sin embargo esta actividad puede amenazar al patrimonio natural y al cultural, pues se han registrado experiencias internacionales que demuestran que ésta causa impactos negativos en el contexto natural, social e incluso económico de las ANP por la infraestructura y los proyectos turísticos no planificados, o por visitaciones no reguladas ni programadas (Ibáñez, 2015). Este crecimiento en visitación, así como el interés por manejarlo apropiadamente, es un fenómeno que también se replica en México dentro de las ANP. Estudios de la Secretaría de Turismo (SECTUR) han encontrado que las ANP son los destinos favoritos para desarrollar actividades de ecoturismo, turismo de naturaleza y de aventura (CONANP, 2006).

\section{Percepciones sociales ambientales}

Aunque los asuntos ambientales sean identificados y evaluados en el dominio de la ciencia, es necesario que esta información se incorpore al sentido común para que sean asumidos como tales. Cuando esto ocurre, los problemas compiten entre sí para ganar atención, legitimidad y recursos sociales (Lezama, 2008; Córdova-Bojórquez y Romo-Aguilar, 2017). Esa es la razón por la que los temas ambientales suelen tener tan baja jerarquía en el ranking de la problemática social, en comparación con asuntos económicos, políticos, educativos, de seguridad o de salud (Bones et al., 2004; Córdova-Bojórquez y Romo-Aguilar, 2017).

El reto que plantean los grandes problemas ambientales a los que nos enfrentamos en la actualidad hace necesaria la formación de ciudadanos capacitados para valorar y participar activamente en su solución (Retamal et al., 2011). Estas situaciones deben abordarse desde una concepción sistémica del medio en la que se visualicen las estrechas relaciones de tipo natural, social, económicas, culturales y políticas que subyacen en toda problemática ambiental (Novo, 2002).

Se identifica que uno de los retos de la moderna sociología ambiental es el análisis de las actitudes, los valores y el comportamiento de la población ante los problemas relacionados con el medio ambiente a escala global (Fernández, 2008; Moyano et al., 2009). Es sobradamente conocido el punto de vista que considera de gran importancia para el estudio de temas ambientales conocer las actitudes, los valores y el comportamiento de la población, dadas las diferencias observadas en el modo como estos problemas son percibidos por los individuos, según el nivel de estudios, la edad, el sexo, el hábitat de residencia o la escala geográfica que se tome como referencia (Cohen et al., 1998; Fernández, 2008).

La complejidad entre la dinámica demográfica, los procesos socioeconómicos y las condiciones ambientales, implica explorar una posibilidad metodológica de investigación que permita entender esta relación (Bilsborrow et al., 1992; UNFPA 1991). Para comprender las relaciones entre las condiciones físico-bióticas, la organización de la producción y la población a nivel regional, las opciones metodológicas parten del concepto de análisis socioambientales a partir de la percepción y conocimientos (Novo, 2002).

Específicamente sobre el impacto del turismo convencional, en la región de procedencia se crea la necesidad de conocer las opiniones y actitudes de los usuarios a ese espacio, el futuro de estas localidades no es solo responsabilidad del gobierno o de los agentes socioeconómicos 
sino principalmente de su población (Ponce, 2004). Para llevar a cabo una óptima planificación estratégica se necesita contar con los puntos fuertes y débiles del destino de referencia y quienes mejor que las personas que ocupan estos espacios como residentes y turistas, para descubrirlos.

La forma en que se transforma el destino turístico es el resultado de la decisión que se adopte entre los propietarios de la tierra, los promotores urbanos y los empresarios turísticos, en este sistema también participan los consumidores directos e intermediarios y el gobierno en sus diversos niveles. Son las relaciones entre estos agentes las que propician una nueva realidad territorial, problemas ambientales, conflictos en la tenencia de la tierra y sus destinos, carencia de infraestructura y finalmente las contradicciones características del urbanismo turístico (Santander, 2005). Al entrar en crisis este modelo turístico-urbanístico ha surgido la necesidad de buscar soluciones y redefinir la visión clásica de los espacios de manera consensuada y tomando en cuenta la opinión de los diferentes actores.

En suma, saber el conocimiento empírico de la población sobre la biodiversidad y su entorno ambiental, es un punto de partida importante e incluyente para que los tomadores de decisiones conozcan su sentir, y actúen en consecuencia (Fernández, 2008), ya que es bien sabido que si las autoridades toman decisiones no consensuadas con las comunidades, es difícil que dichas comunidades se integren adecuadamente al trabajo en equipo, por un bien u objetivo común, sobre todo en zonas prioritarias como lo son las ANP (Olmos-Martínez et al., 2013a, 2013b).

Es por eso que el estudio de las relaciones entre la opinión pública y las políticas ambientales admite los esfuerzos en gasto público realizados por los gobiernos en esta área y se explican por la influencia que ejerce la población (Dunlap, 1995; Novo, 2002). Se admite también que tal influencia se debe menos a la preocupación de la ciudadanía por el deterioro general del medio ambiente que a la importancia que le atribuye la población a temas ambientales específicos de especial sensibilidad, a escala local o regional y de fuerte incidencia en los comportamientos o estilos de vida (Barr, Gilg y Ford, 2003; Fernández, 2008).

Finalmente, resulta relevante contar con estudios sobre la relación población-ambiente que permitan comprender de qué manera los procesos demográficos, políticos y/o económicos inciden en el deterioro y/o cuidado ambiental (Fernández, 2008). Entender la dinámica demográfica de la región y en particular su vinculación con el cambio de uso del suelo permitiría avanzar en la búsqueda de alternativas de desarrollo y adaptación, las cuales contemplan la prevención del agotamiento de los recursos naturales, y mantener las actividades productivas y la calidad de vida de los habitantes (Lezama, 2008).

\section{Área de estudio y el contexto local}

El estado de BCS es una región geográfica privilegiada que posee un valor natural, histórico y cultural de gran relevancia tanto nacional como internacional, por presentar entre otras razones, un elevado número de ANP localizadas en su mayoría en el Golfo de California (OlmosMartínez, 2013b). BCS es el estado de mayor extensión costera en la República Mexicana, con más del $40 \%$ de su superficie decretada como ANP, así como el de mayor diversidad de recursos marinos de México, destacando por su fisiografía, el Municipio de Los Cabos (Gob. de BCS y SAGARPA, 2011).

De acuerdo con los criterios elaborados por el panel de expertos de la Comisión Nacional para el Conocimiento y Uso de la Biodiversidad (CONABIO), la Región del Cabo es considerada como una de las 19 Provincias Biogeográficas del país (CONABIO, 1997). Asimismo, en la regionalización biogeográfica del Atlas de México del Instituto de Geografía de la Universidad Nacional Autónoma de México (Ferrusquía-Villafranca, 1992), la Región del Cabo es considerada como una zona de transición entre diferentes dominios biogeográficos.

En el municipio de Los Cabos se encuentran cinco zonas para la protección y conservación de recursos naturales, destacando el Estero San José del Cabo (ESJC) por su importancia tanto ambiental como económico, social y cultural de gran tradición para la comunidad 


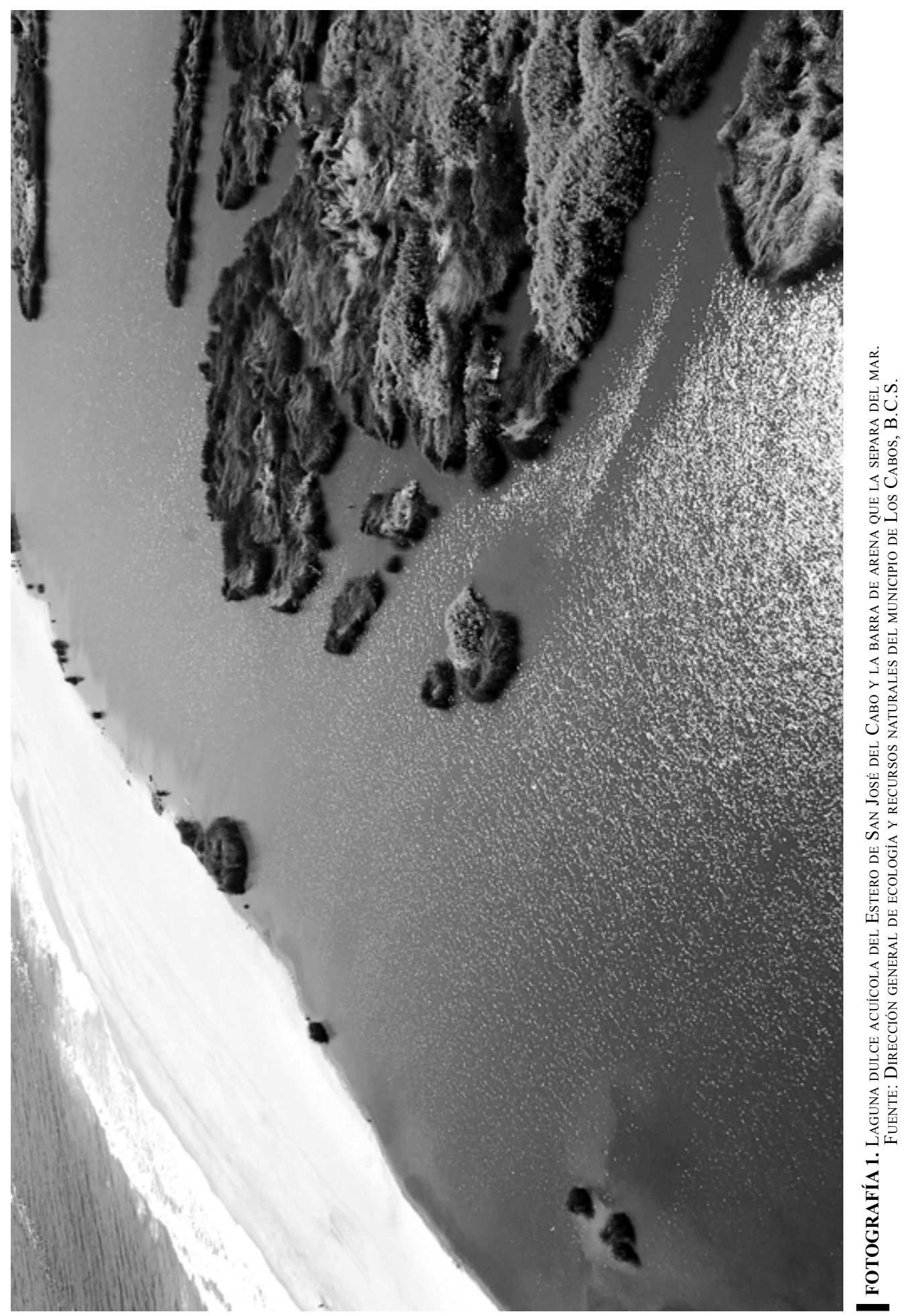


municipal (Armenta, 2015). Dentro de esta región biogeográfica, se encuentra la única laguna costera dulceacuícola representada por el ESJC (fotografía 1), por tal motivo, el humedal es considerado de importancia internacional y es declarado como un sitio de importancia internacional como hábitat de aves acuáticas (sitio RAMSAR) y área de importancia para la conservación de las aves (CONABIO, 1997). La declaratoria tuvo como objeto armonizar la recuperación, la preservación y el desarrollo socioeconómico a través del adecuado manejo de los recursos naturales y promover la investigación, enseñanza y participación de la población local (CONABIO, 1997). Los factores adversos más importantes mencionados en la declaratoria RAMSAR como principal problemática en el ESJC, se enmarcan en el cambio de uso del suelo, el crecimiento urbano de San José del Cabo y la elevada presión generada por los desarrollos turísticos (Armenta, 2015).

El ESJC es un ecosistema de gran relevancia hídrica y biológica para la región debido a que alberga especies vegetales únicas y constituyen importantes corredores y refugios de flora y fauna (fotografía 2), características que además son de gran relevancia para la actividad turística de la zona (boletín oficial Gobierno del Estado de Baja California Sur, 1994; Armenta, 2015). Es también una zona de belleza paisajística al contrastar con el entorno árido de la región, por lo que desde hace décadas es zona de recreo de los pobladores locales y de actividades de avistamiento de aves, paseos a caballo y en lanchas, justo en el centro de uno de los sitios turísticos importantes de Los Cabos (Armenta, 2015, OlmosMartínez et al., 2016).

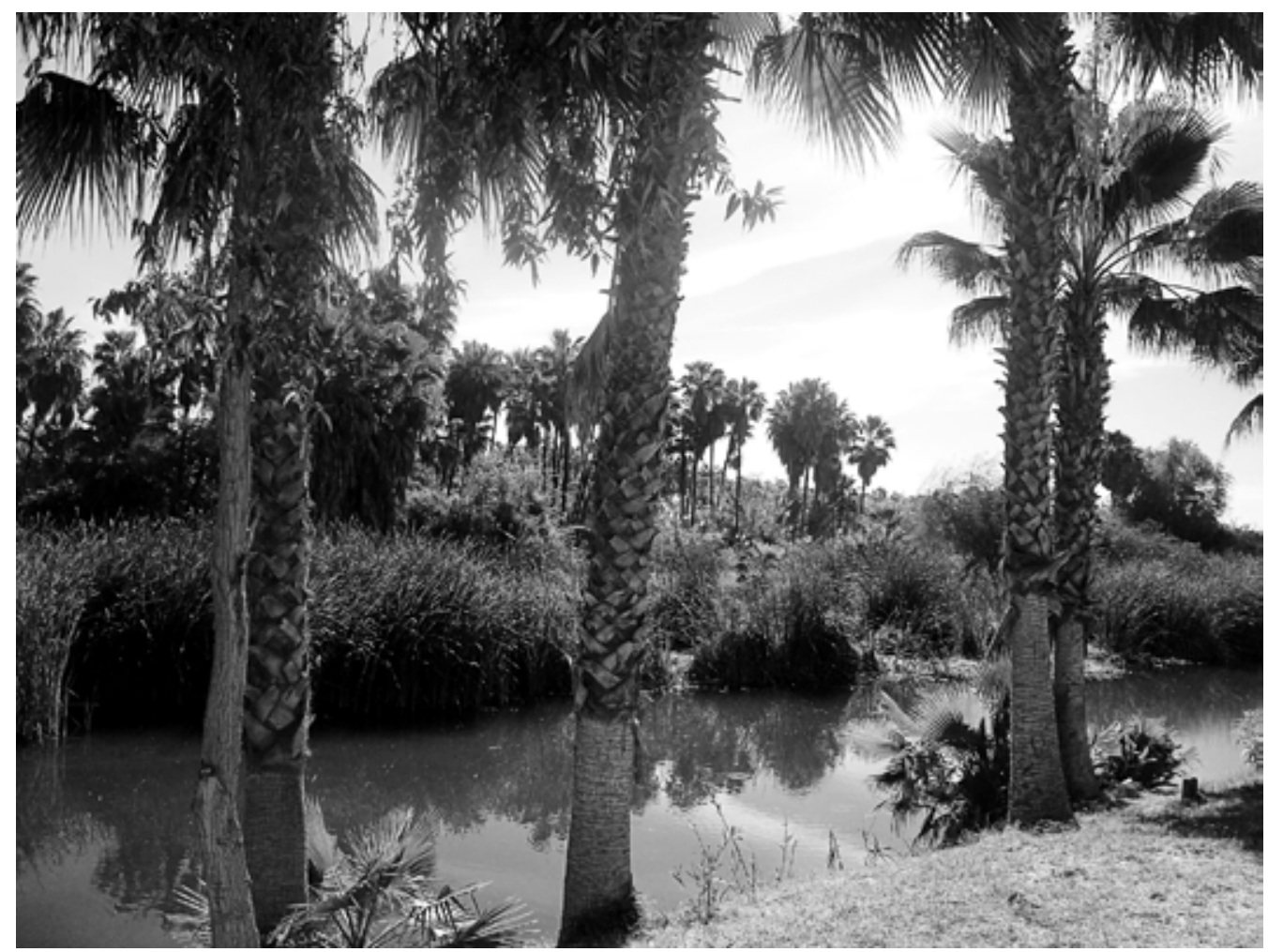

FOtOGRAFía 2. Paisaje de la Reserva Ecológica Estatal Estero de San José del Cabo. Fuente: Elizabeth Olmos-Martínez 


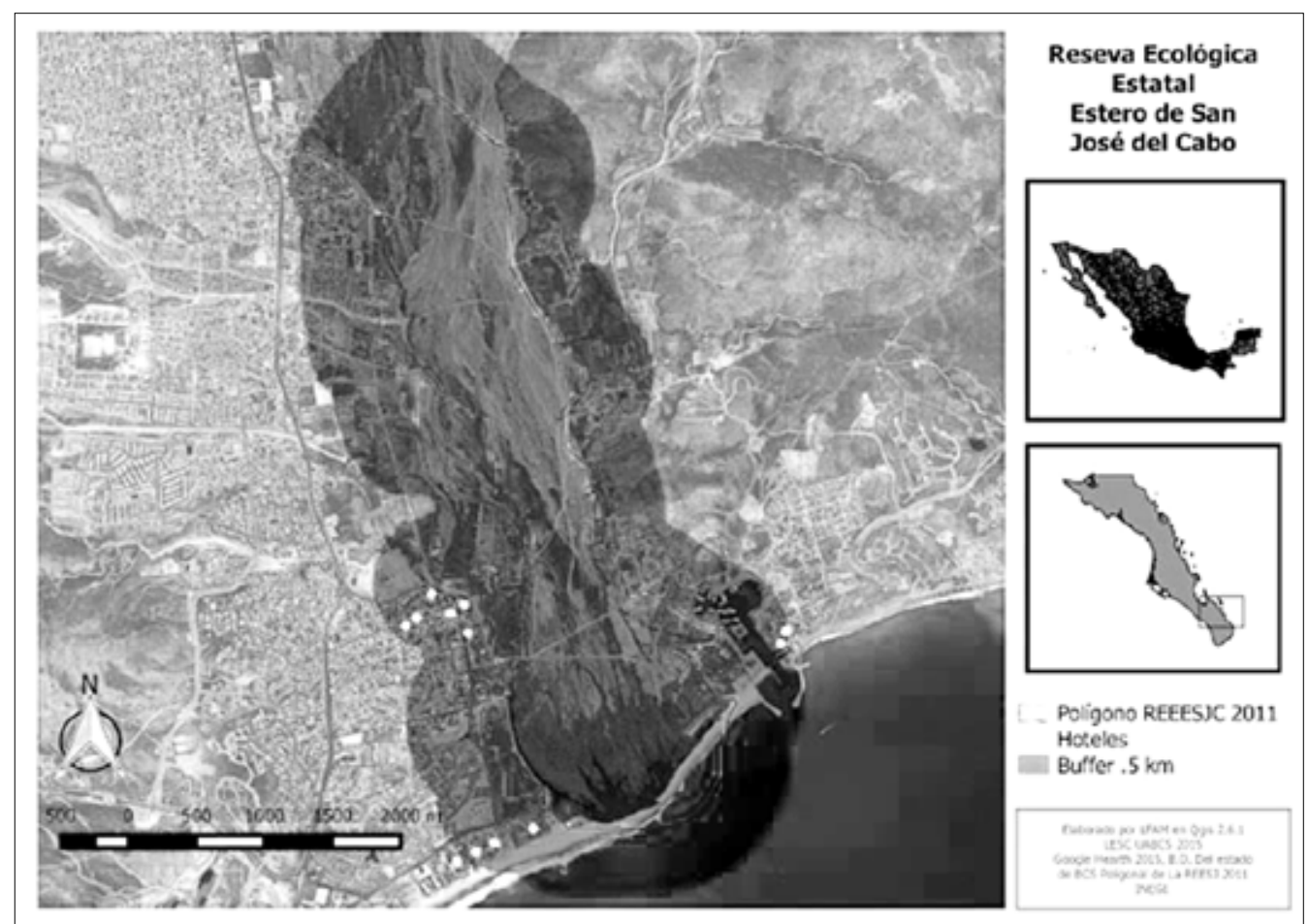

MAPA 1. Localización de la Reserva Ecológica Estatal Estero de San José del Cabo. Fuente: Armenta, 2015.

En 1993, el ESJC fue declarado Reserva Ecológica Estatal, bajo la categoría de Zona Sujeta a Conservación Ecológica, el nombre oficial es Reserva Ecológica Estatal Estero de San José del Cabo (REEESJC), la autoridad gubernamental con jurisdicción sobre la reserva es el gobierno del municipio de Los Cabos. Asimismo, la declaratoria tuvo como objeto armonizar la recuperación, la preservación y el desarrollo socioeconómico a través del adecuado manejo de los recursos naturales y promover la investigación, enseñanza y participación de la población local (Armenta, 2015). Durante los últimos 20 años el polígono de la reserva ha sufrido varias modificaciones, la última declaratoria fue el 4 de abril de 2011 con un cambio en la extensión de 512-229 hectáreas a 766-684 hectáreas (mapa 1) (boletín oficial del Gobierno del Estado de Baja California Sur, 2011).

Asimismo, la localización geográfica ubica a la reserva en una situación vulnerable, al colindar al Este, al Norte y al Oeste con centros de población, estos ejercen una presión sobre la reserva y sus ecosistemas, sobre todo cuando estas localidades alrededor del estero concentran el $22 \%$ de la población total estatal (INEGI, 2010) y más del $50 \%$ de la infraestructura hotelera (Armenta, 2015). Las principales problemáticas detectadas en la reserva son: a) construcción irregular de instalaciones dentro de la reserva, así como caballerizas y renta de motos; b) deforestación por aprovechamiento ilegal de hoja de palma y extracción de palma completa ((Washingtonia robusta); c) tiradero de escombro, desechos vehiculares y basura cauce arriba del estero; d) proceso con tendencia a urbanización; e) introducción de especies exóticas de flora y fauna; f) deterioro frecuente de la vegetación por quema e incremento de incendios; y, g) fragmentación del paisaje y la hidrología, por veredas y caminos, con sustitución de ambiente natural por ambiente modificado por el humano (boletín oficial Gobierno del Estado de Baja California Sur, 2010; Armenta, 2015; Olmos-Martínez et al., 2016). 


\section{Metodología}

Durante 2016 se aplicó una encuesta dirigida especialmente a autoridades (municipales, estatales y federales), empresarios, grupos sociales y organizaciones de la sociedad civil que comparten intereses relacionados con el manejo y conservación de la REEESJC y que desarrollan sus actividades (económicas, de conservación y manejo) dentro de la zona de influencia del estero (500 metros de la línea poligonal del área).

El instrumento de recolección de datos incluye variables cuantitativas y cualitativas. Se compone de tres secciones: 1) identificación de los actores; 2) conocimiento y percepción de la conservación y uso de recursos naturales; e, 3) identificación de amenazas ambientales. Cabe mencionar que en la sección de resultados se detalla la organización de las secciones, a mayor detalle, para la mejor comprensión de estos.

La encuesta se aplicó durante una sesión ordinaria del Instituto Municipal de Planeación (IMPLAN) del Municipio de Los Cabos, específicamente a este grupo de actores clave, quienes toman las decisiones localmente. Cabe mencionar que el total de asistentes a la sesión ordinaria del IMPLAN fue de 25 personas, por lo que el tamaño de la muestra probabilística se calculó a partir de lo recomendado para estudios cualitativos y fenómenos sociales de acuerdo con Calero (1978) y Hernández Sampieri et al. (2014), la cual resultó de 24 personas, con $95 \%$ de confianza y $5 \%$ de error. En la muestra destacan diferentes dependencias de gobierno federal (Comisión nacional de áreas naturales protegidas), estatal (Dirección de desarrollo sustentable) y municipal (Dirección general de ecología), así como organizaciones de la sociedad civil (Colegio de arquitectos e ingenieros civiles, organizaciones ambientalistas) y empresarios locales (sector hotelero e inmobiliario) localizados en la zona de influencia.

Se trata de un estudio transversal donde la información se ha recogido una única vez en un periodo de tiempo delimitado y de una población definida. Para el análisis de algunas preguntas se utilizó la escala de Likert, se trata de un nivel ordinal y ayuda a conocer prioridades de los encuestados, donde las respuestas varían entre 1 y 3 ( $1=$ bueno, $2=$ recular y $3=$ malo) y entre 1 y 5 ( $1=$ excelente, $2=$ bueno, $3=$ regular, $4=$ malo y $5=$ muy malo $)$.

\section{Resultados}

De acuerdo con las visitas de campo y las encuestas aplicadas existen ocho comunidades que colindan e interactúan con el estero ejerciendo presión en el ecosistema, 14 hoteles y diversos comercios, todos relacionados con servicios turísticos. La localización geográfica ubica a la reserva en una situación vulnerable ya que, al colindar al Oeste con la ciudad de San José del Cabo, al Norte con las poblaciones de Santa Rosa y Ánimas altas, al Este con el poblado La Playa, estas ejercen una presión sobre la reserva y sus ecosistemas. Las localidades alrededor del estero concentran el $22 \%$ de la población total estatal (INEGI, 2010) y más del $50 \%$ de la infraestructura hotelera (Armenta, 2015).

\section{Análisis de la encuesta por sección}

\section{Sección 1. Identificación de los actores}

Del total de encuestados, el sector empresarial representa $31 \%$; $23 \%$, representan a las organizaciones de la sociedad civil; $23 \%$, a las autoridades municipales; $15 \%$, a las autoridades del gobierno estatal y $8 \%$, representa a las autoridades del gobierno federal. Por otro lado, la mayoría ( $80 \%$ ) de los encuestados es género masculino y $67 \%$ reportaron tener nivel universitario en su escolaridad. 


\section{Sección 2. Conocimiento y percepción de la conservación, sustentabilidad y uso de recursos naturales}

El $62 \%$ de los encuestados opinan que los recursos naturales de la reserva se encuentran en estado regular, $21 \%$ en buen estado y $18 \%$ en mal estado; asimismo solo el $50 \%$ de los encuestados dijeron conocer la normatividad ambiental que le atañe a la reserva, cuando se le preguntó qué normatividad, sus respuestas fueron: la Ley General del Equilibrio Ecológico y la Protección al Ambiente, la Ley General de Vida Silvestre, la Ley Estatal del Equilibrio Ecológico y la Protección al Ambiente, Plan de Manejo del Estero San José, la denominación de Área Natural Protegida Estatal y de la Zona Federal Marítimo Terrestre.

Según la percepción de los encuestados, sobre el manejo y uso de los recursos naturales, $86 \%$ lo califican como "regular" argumentando falta de conocimiento de programas, mucho desorden, falta de interés por los habitantes y falta de vigilancia de las autoridades. Para las políticas gubernamentales de conservación y aprovechamiento de recursos naturales que según los encuestados conocen que se han llevado a cabo, $79 \%$ dice conocer el plan de manejo de la REEESJC y $36 \%$ conoce los programas de empleo temporal que se implementan por el gobierno estatal y municipal.

De acuerdo con el programa de manejo del ANP, solo 43\% de los encuestados conocen las actividades permitidas y prohibidas destacando las relacionadas con el turismo tales como, senderismo, observación de aves, tierra y fauna, así como fotografía y paseos; asimismo, argumentaron que las actividades no permitidas son cabalgatas, paseos en moto y pesca, sin embargo, se realizan sin permisos ni sanciones.

Sobre el conocimiento de la infraestructura existente y oferta de servicios disponible para el soporte de las actividades turísticas $71 \%$ reconoce los servicios municipales, $50 \%$ servicios de comunicación y carreteras, $29 \%$ transporte entre otras.

Es muy importante que dentro de un grupo de actores locales que representan diferentes esferas sociales y que proponen y deciden las estrategias de manejo en un ANP, den a conocer las prioridades que deben tomar en cuenta las autoridades administrativas, es por eso que al cuestionarles sobre las acciones prioritarias que deben tomar en cuenta los administradores del ANP los resultados muestran las siguientes opciones: conservación (36\%), rehabilitación/ restauración (36\%), vigilancia $(29 \%)$, inversión (para las actividades propias de las autoridades administradoras del área) (21\%) y en menor medida acercamiento y trabajo con la sociedad (14\%).

A los encuestados se les pidió que seleccionaran sobre diferentes valores (ambientales, sociales y económicos) que las autoridades deben tomar en cuenta para la realización de las políticas públicas y estrategias para alcanzarlas; el resultado muestra que $93 \%$ opina que el ambiente tiene más valor, muy por encima del $36 \%$ sobre la economía.

Referente a los principales problemas y/o amenazas para la conservación del estero, dentro de las 11 opciones de respuesta del cuestionario, se encontró que $86 \%$ opina que el principal problema es el desconocimiento del plan de manejo por los actores involucrados; $79 \%$, falta de participación de la sociedad; 71\%, falta de divulgación de la importancia del Estero SJC; 57\%, elevada incidencia de los incendios forestales; $50 \%$, generación de contaminantes orgánicos e inorgánico y $50 \%$ falta de participación de los administradores del ANP; $42 \%$, falta de servicios municipales; $41 \%$, actividades recreativas de los prestadores de servicios turísticos; $36 \%$, falta de capacitación del personal a cargo del manejo, conservación y vigilancia del área; $28 \%$, urbanización y desarrollos turísticos y $7 \%$, pesca ribereña.

\section{Sección 3. Identificación de amenazas ambientales}

Es menester mencionar que esta sección de la encuesta se sub-divide en cinco categorías de análisis para la identificación de las amenazas ambientales en cada una de ellas, dichas categorías son las siguientes:1) Salud del ambiente en general (seis opciones de respuesta), 2) Zona costera 
(cinco opciones de respuesta), 3) Uso de suelo (cuatro opciones de respuesta), 4) Recurso agua (seis opciones de respuesta),y 5) Sociedad (ocho opciones de respuesta); para cada una de las categorías se solicitó indicaran su percepción en grados de importancia de aspectos amenazantes del uno al tres, donde uno es la principal amenaza.

En la primer categoría, Salud del ambiente en general, los resultados muestran como amenaza principal los fenómenos hidrometeorológicos adversos y la pérdida de hábitats de mamíferos, aves y reptiles; en segundo lugar se encuentra, la reducción de superficie forestal por cambio en uso de suelo; finalmente, la pérdida o desplazamiento de fauna por cambios en la vegetación por el uso de suelo (gráfico 1). Se observa que las principales amenazas están relacionadas con los fenómenos hidrometeorológicos y los estragos que se derivan de dichos fenómenos, cabe mencionar que el área de estudio se ubica geográficamente en una región de alto riesgo y vulnerabilidad (INE-SEMARNAT-UABCS-CIB-CICIMAR-CICESE-CONACYT-Gob. del estado de BCS, 2012).

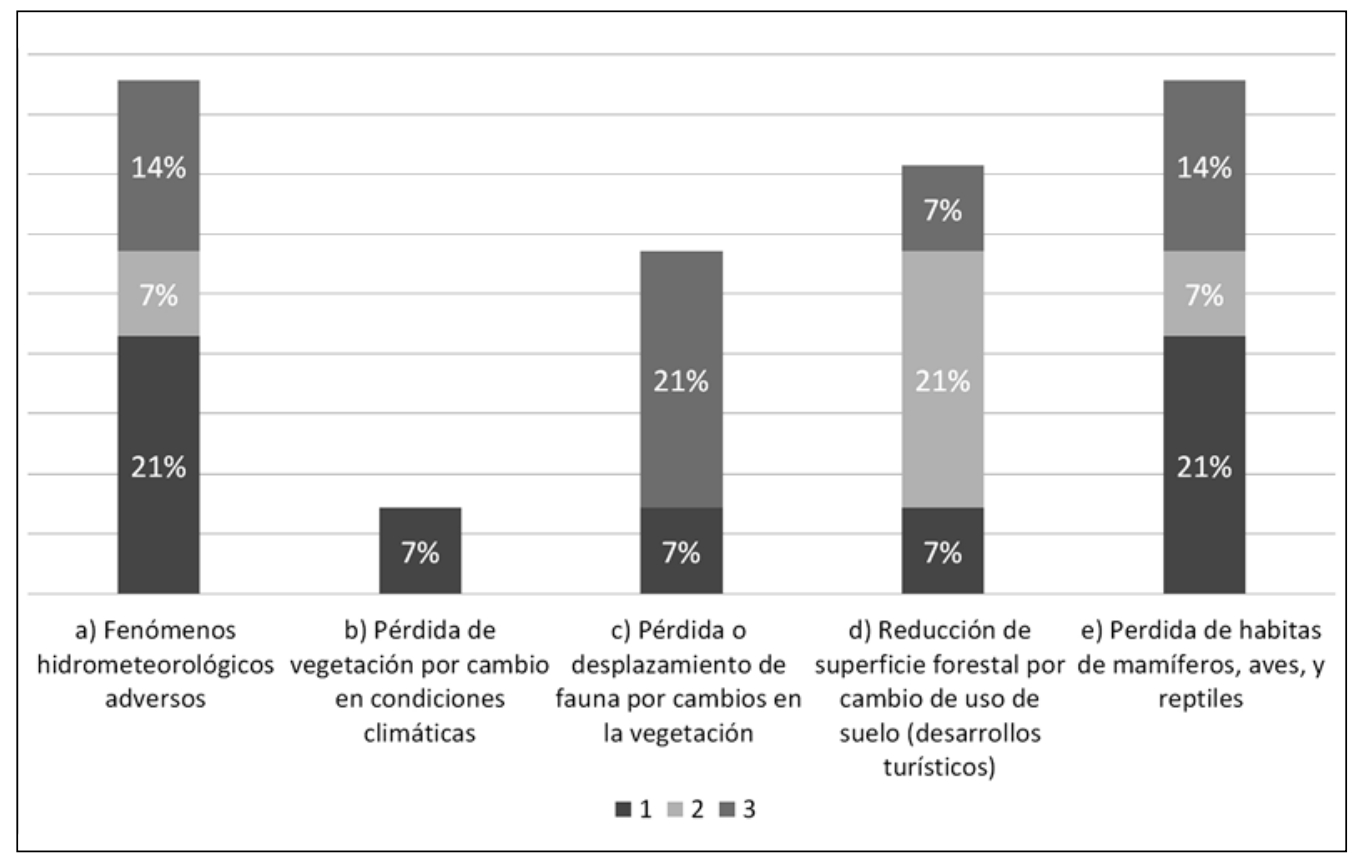

GRÁfiCO 1. Percepción de grados de importancia de amenazas a la SAlud del ambiente en General (PRIORIDAD DEL 1 AL 3). FUENTE: ELABORACIÓN PROPIA.

En la segunda categoría, Zona costera, la amenaza principal es la contaminación de playas, seguida del incremento en el nivel del mar y la reducción de la zona costera (área de playa) (gráfico 2). Se observa que los encuestados tienen muy claro que la contaminación de las playas es un problema grave, al respecto se sabe que en la zona de influencia de la REEESJC se realizan actividades (turismo, planta de tratamiento de aguas residuales, construcción de infraestructura, etc.) que por falta de planeación, inspección y vigilancia contaminan la zona costera (Armenta, 2015); asimismo, el tema del incremento del nivel del mar es tratado en diversos estudios (INESEMARNAT-UABCS-CIB-CICIMAR-CICESE-CONACYT-Gob. del estado de BCS, 2012; Armenta, 2015; Ayuntamiento de Los Cabos, 2016) y se cataloga como vulnerabilidad de la zona de estudio ante el cambio climático. Dado lo anterior, la percepción de los encuestados se fortalece y corrobora con las publicaciones recientes sobre el tema de amenazas en el área de estudio. 


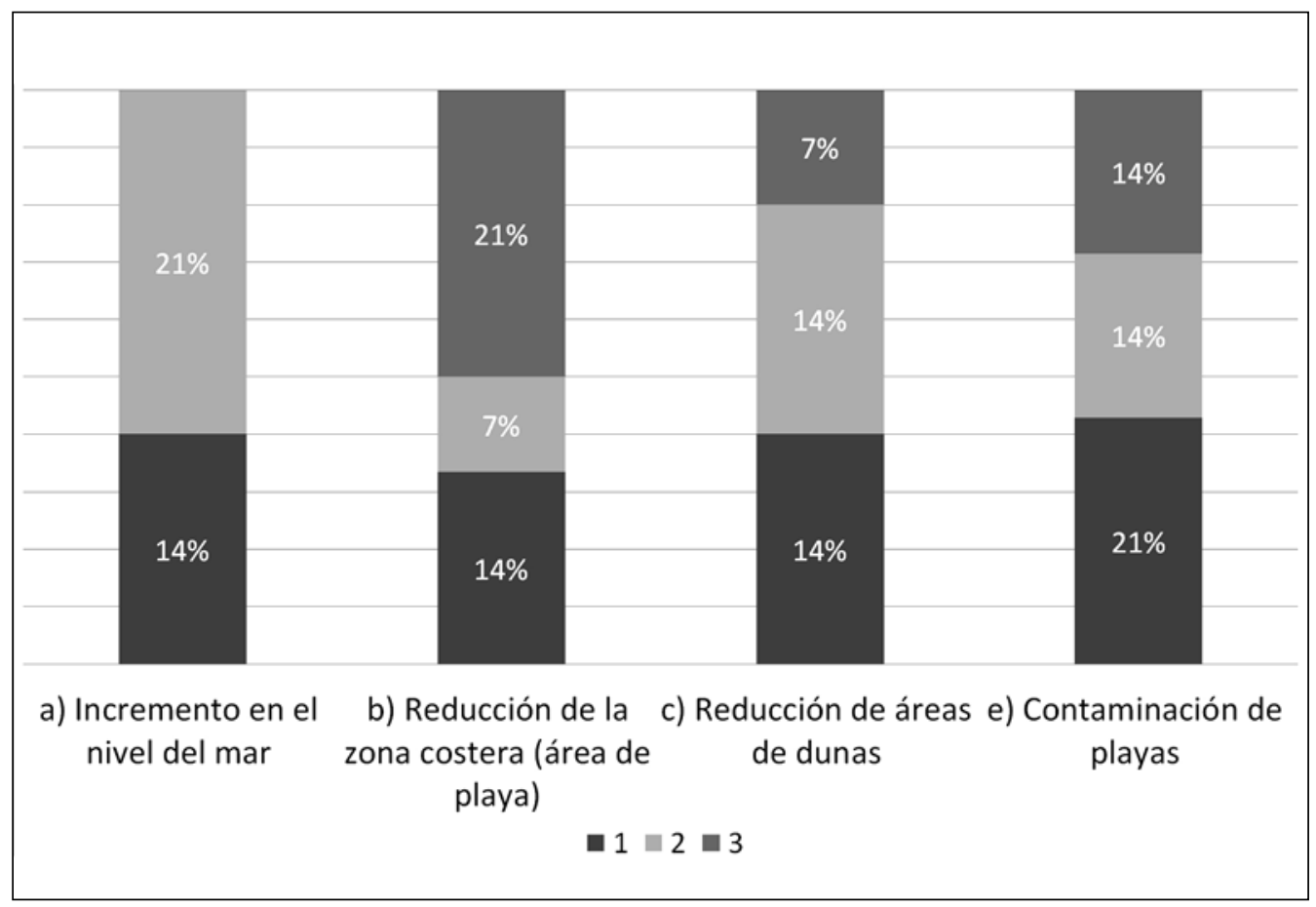

GRÁFico 2. Percepción de grados de importancia de AMENAZAS a LA ZONA COSTERA (PRIORIDAD DEL 1 AL 3 ) FuENTE: ElABORACIÓN PROPIA.

Para el análisis de la tercera categoría, Uso de suelo, se encontró que la amenaza principal es el aumento de sequías, seguido de erosión/deterioro de suelos y pérdida de suelo productivo (gráfico 3). Cabe señalar que en la gráfica se muestran solo las opciones que fueron seleccionadas. Al respecto, existen diversos estudios relacionados con sequías y erosión de suelos (INE-SEMARNAT-UABCS-CIB-CICIMAR-CICESE-CONACYT-Gob. del estado de BCS, 2012; CONAGUA, 2014) que señalan que además del incremento de la fuerza de los fenómenos hidrometeorológicos también se padecen sequías pronunciadas que amenazan a todo el estado de BCS.

Sobre la cuarta categoría del análisis, Recurso agua, la principal amenaza es el cambio en el volumen y calidad del flujo superficial, seguido de frecuencia e intensidad de huracanes, lluvias más intensas y/o menos frecuentes y finalmente la amenaza número tres es desaparición de cuerpos de agua superficiales, en la gráfica solo se muestran las opciones que fueron seleccionadas como prioridades del 1 al 3 (gráfico 4). Al respecto, diversos estudios (INESEMARNAT-UABCS-CIB-CICIMAR-CICESE-CONACYT-Gob. del estado de BCS, 2012; CONAGUA, 2014, Armenta, 2015) coinciden con la percepción de los encuestados ya que mencionan que han detectado cambios en el volumen de los cuerpos de agua superficiales, incluso su desaparición.

En la quinta categoría, Sociedad, las amenazas prioritarias son las siguientes, falta de agua en viviendas aledañas al estero, dificultad en el acceso a las colonias por caminos deteriorados y cambio en las actividades sociales a causa de climas extremos (gráfico 5). Al respecto estudios recientes (Armenta, 2015, Robles et al., 2018) muestran que de las ocho comunidades que se ubican en la zona de influencia de la REEESJC todas tienen rezagos y falta de agua, problemas de acceso a las comunidades más alejadas y vulnerabilidad social. 


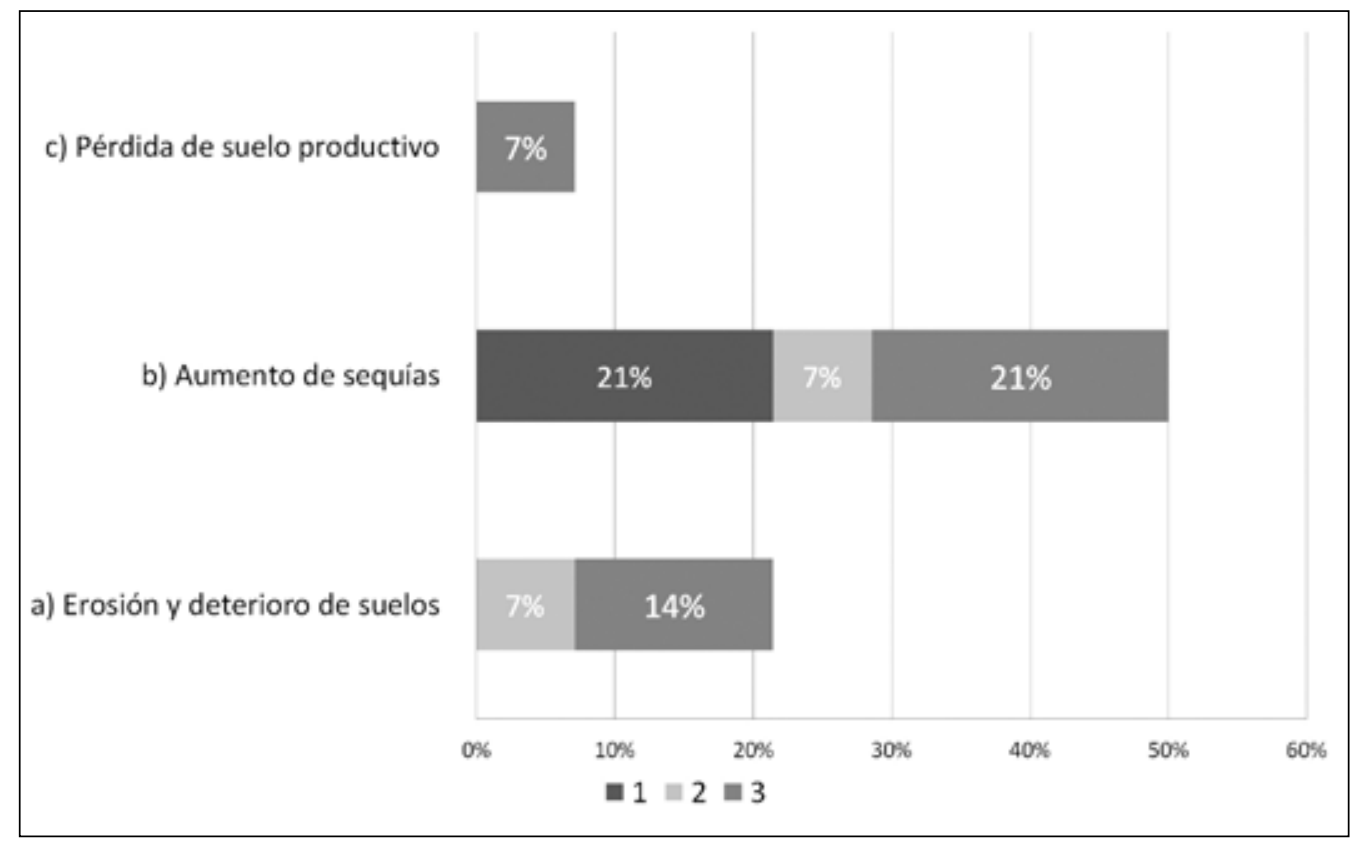

GRÁFiCO 3. Percepción de grados de importancia de amenazas en el uso de suelo (PRioridad del 1 AL 3 ) Fuente: Elaboración Propia.

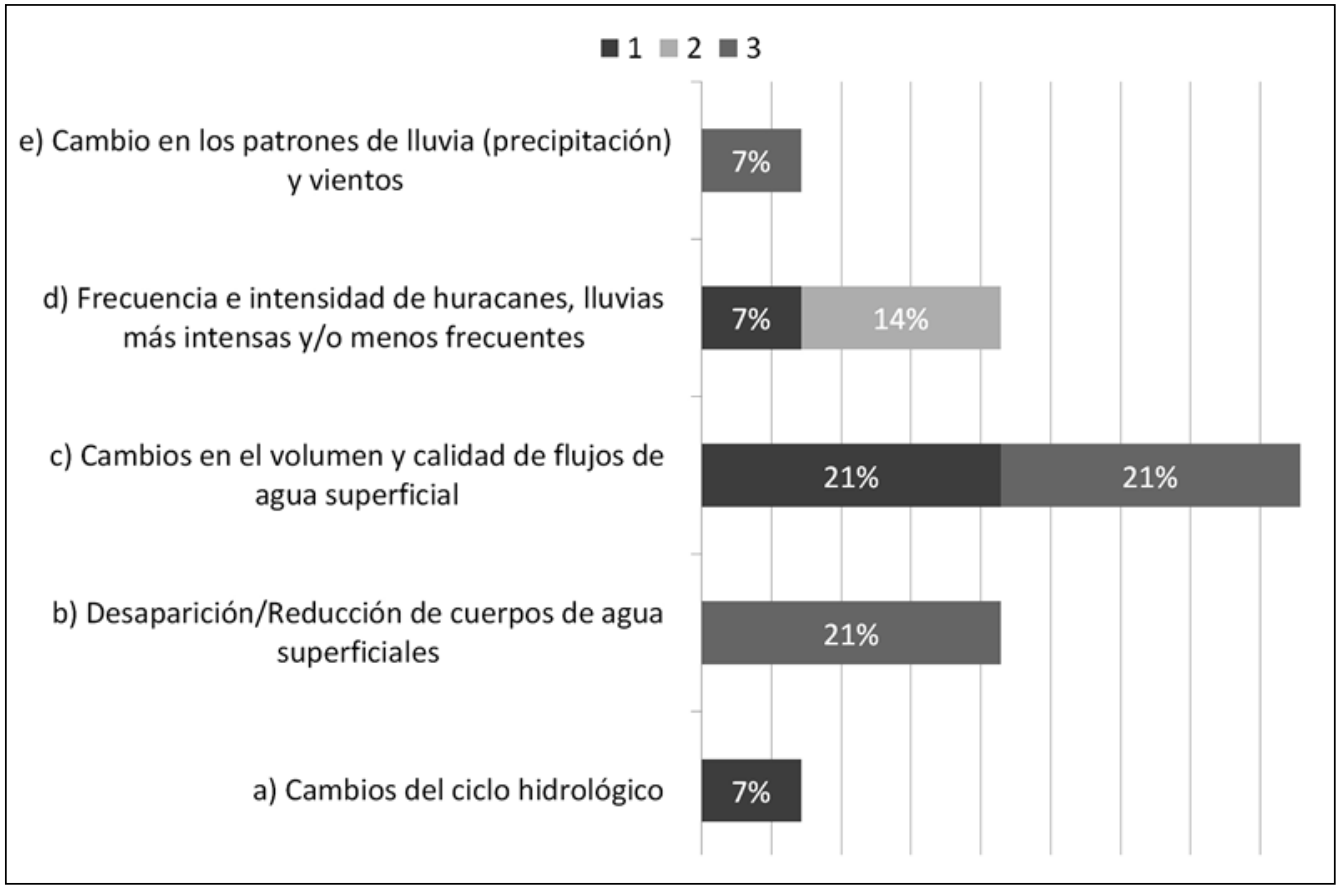

GRÁFiCO 4. Percepción de grados de importancia de amenazas sobre el ReCurso agua (PRioridad del 1 al 3 ) FUENTE: ELABORACIÓN PROPIA. 
g) Pérdida de estabilidad de salud a causa de las olas de calor y alta humedad

f) Destrucción de viviendas por huracanes o tormentas

e) Enfermedades infecciosas por la presencia de virus o bacterias ambientales

d) Cambio en las actividades sociales a causa de climas extremos

c) Aislamiento de colonias

b) Dificultad en el acceso por caminos deteriorados por huracanes

a) Falta de agua en viviendas aledañas al ESJC

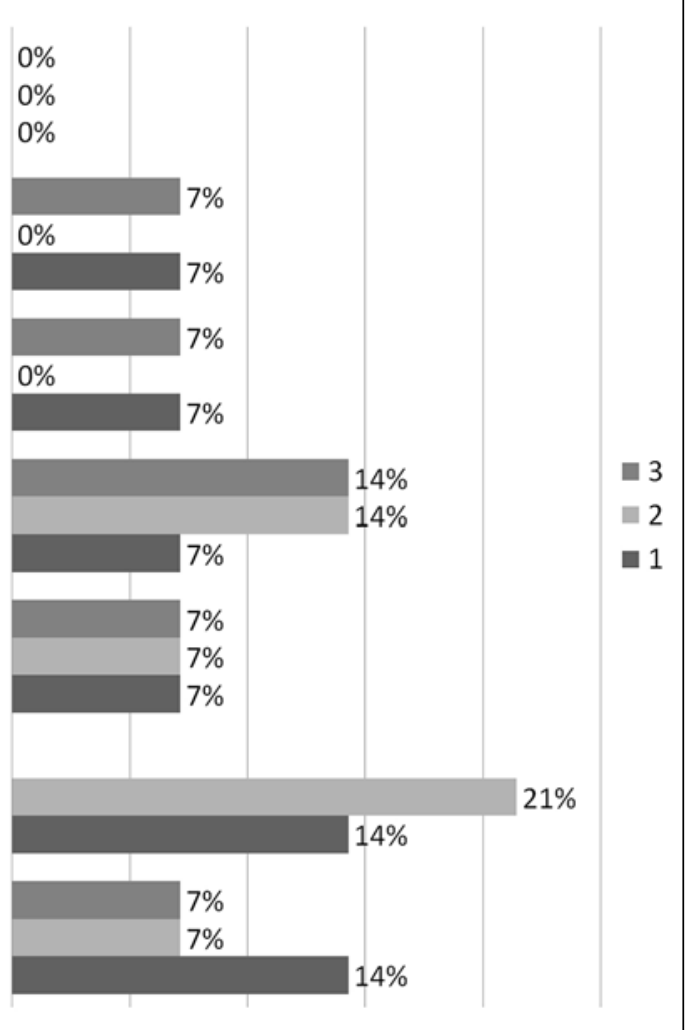

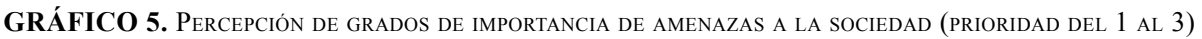
Fuente: Elaboración PROPIA.

\section{Discusión}

La zona de estudio se caracteriza por una presión humana principalmente debido al desarrollo económico del turismo en los alrededores de la REEESJC (Armenta, 2015). Para 2012, en el municipio de Los Cabos se contabilizan 12,621 habitaciones, 52\% de esos cuartos de hotel se ubican en Cabo San Lucas, 28\% en el corredor turístico (entre Cabo San Lucas y San José del Cabo) y $20 \%$ en San José del Cabo, este total de habitaciones se distribuye en 80 hoteles, de los cuales 40 se encuentran en Cabo San Lucas, 21 en San José del Cabo y 19 en el corredor turístico (Dirección Municipal de Turismo de Los Cabos, 2015).

Del total de 14 hoteles ubicados en la zona de influencia de la REEESJC, todos ellos desarrollan actividades en la REEESJC tales como caminatas, paseos en bicicleta, avistamiento de aves, recorrido fotográfico, entre otras (información obtenida de los sitios de internet de cada hotel).

El sector turismo versus el sector de desarrollo urbano tiene un efecto positivo, ya que influye claramente en la generación de empleo directo e indirecto y deja una derrama de divisas importante para el municipio de Los Cabos (ayuntamiento de Los Cabos, 2016). No obstante, el sector turismo versus el sector de conservación ambiental puede tener dos efectos: por un lado el efecto negativo, representado por un gran número de visitantes en términos de la presión sobre los recursos; sin embargo, y por otro lado, como gran parte del turismo que recibe el municipio 
es de origen extranjero, la cultura hacia el medio natural es diferente y en muchos casos son más respetuosos de las medidas de conservación, incluso el turismo extranjero practica más el ecoturismo o turismo de naturaleza respecto al turismo nacional y en este sentido puede ejercer un efecto positivo (Armenta, 2015).

Aun cuando se identifica la relevancia biológica en la zona, las autoridades y grupos de interés (empresarios y líderes comunitarios) que se encargan de la planeación de las actividades turísticas que se realizan en la REEESJC y su zona de influencia, desconocen información relevante que les permitiría conocer, identificarse, valorar y proponer acciones de conservación eficaces frente al reto de la sustentabilidad del ANP.

Se sabe que la percepción de la población (en este caso de los tomadores de decisiones) sobre la importancia de la conservación de un área natural, está estrechamente relacionada con el grado de conocimiento que tienen de la misma y el valor intrínseco de la biodiversidad, por lo que es necesario contar con campañas de información y eventos que involucren a todos los actores que interactúan en la zona.

Al encontrarse la REEESJC dentro de la mancha urbana del centro turístico de San José del Cabo, se incrementa la vulnerabilidad ambiental ya que existen sucesos como contaminación del cuerpo de agua, actividad agrícola, existencia de ganado para pastoreo que persiste dentro del polígono, incremento de incendios, así como desarrollos turísticos que compiten por un espacio territorial donde la naturaleza les ofrece mayores beneficios económicos debido a la demanda creciente de turistas que buscan lugares con biodiversidad y espacios naturales para su disfrute (Olmos-Martínez et al., 2016).

En ese sentido, aunque las autoridades y grupos de interés en el estero reconozcan que existe un problema de conservación ambiental y estén informados de un modo general de su importancia, no significa que les resulte fácil identificar las prioridades, siendo esta dificultad un asunto de máxima importancia a la hora de orientar las políticas de recuperación, manejo y conservación.

En cuanto a la concordancia de los resultados de esta investigación con estudios cabe destacar, que los trabajos desarrollados para la zona hacen énfasis ya sea en el valor biológico del sitio o bien, en las características y consecuencias generales del desarrollo de la actividad turística en el municipio donde se localiza la zona.

En este último, caso destacan trabajos de Ibáñez (2015) donde se analizan las problemáticas socio ambientales de San José del Cabo, mediante información documental y entrevistas con agentes clave y se destaca que, esa ciudad posee características que la distinguen de otros sitios y esto, se debe a su pasividad, a la presencia de atractivos eco sistémicos, además de un creciente interés de los hoteleros, en relación a la adopción de energías alternas no obstante, para identificar alternativas para su desarrollo y consolidación en materia de competitividad, se requiere de planificación ambiental y del uso de la tierra.

Por su parte, López y Sánchez (2002) al analizar, los canales espaciales de articulación en el corredor turístico Los Cabos, BCS, México, concluyen que, existe una fuerte participación extranjera en diversos ámbitos por lo que, el tema de la soberanía nacional fue una de las principales problemáticas detectadas adicionalmente, se hicieron énfasis en el estado deficiente de la infraestructura y servicios de comunicación orientada a la población local y regional. Por otra parte, en la investigación efectuada por Ibáñez et al., (2016) a partir de un estudio del índice de satisfacción destino turístico de Los Cabos, emitieron como recomendación, el establecimiento de canales de comunicación con los diferentes agentes que participan en el desarrollo turístico, para la implementación de medidas que favorezcan el aprovechamiento sustentable y equitativo del potencial de Los Cabos.

Así también, en estudios realizados por Ibáñez (2016), donde se estima el nivel de sustentabilidad de Cabo Pulmo y en BCS, una serie de indicadores arrojó que, el nivel de sustentabilidad turística para ambos sitios fue evaluada como buena no obstante, el grupo de indicadores medioambientales obtuvo un desempeño menor con respecto a indicadores asociados 
a variables socioeconómicas, situación que reveló la necesidad de trabajar en la introducción de mejoras urgentes para mejorar la calidad del agua para consumo doméstico y turístico, para reducir la captura ilegal de especies, las modificaciones en el paisaje derivado de la expansión de complejos turísticos que ocasiona pérdida de manglares y la explotación de mantos acuíferos primordialmente en los destinos turísticos del municipio de Los Cabos.

Finalmente, Martínez et al., (2013) señalaron que, Los Cabos, BCS presentaba un buen nivel de desarrollo humano pero altos niveles de pobreza y marginación, pero, aun así, se encontró que, en algunas colonias populares, la percepción de la población en relación al bienestar fue considerado como bueno.

Como puede apreciarse si bien la literatura es basta con relación a temas de sustentabilidad y turismo son escasos los trabajos donde se integre la opinión de la población, sobre el tema de la sustentabilidad, razón por lo cual, es imposible evaluar mediante un comparativo con trabajos previos los cambios en la percepción de la población asentada en zonas adyacentes a la zona de estudio.

\section{Conclusiones}

La expansión del turismo debe conllevar la implementación de estrategias que garanticen la conservación de los recursos naturales y culturales del país. Lo anterior, es especialmente apremiante en zonas alta riqueza natural. No obstante, la mera existencia de leyes, reglamentos y programas en materia ambiental no garantiza la conservación de tales áreas.

La correcta aplicación de instrumentos de planeación ambiental debe ser acompañada con la participación de la población. En este sentido, los logros en materia de conservación no deben basarse solo en indicadores y metas burocráticas también demandan la integración de la percepción de la población, situación que incluso se justifica en términos constitucionales pues, se establece la necesidad de ejercer una planeación participativa del desarrollo. Conocer la opinión de la población con relación a la forma en que se aplican las medidas de conservación y manejo, así como sus impactos en el nivel de sustentabilidad, representa una oportunidad para obtener información que permita reorientar, reforzar e implementar acciones para robustecer las medidas originalmente contempladas.

En este caso, el estudio realizado arrojó que, la percepción de la sustentabilidad en el área turística ESJC, revela que la principal problemática versa en la falta de conocimiento del plan de manejo, por parte de los actores locales. Aún con tal desconocimiento, opinan que las estrategias prioritarias de manejo deben ser la conservación y vigilancia. Así también, las autoridades y grupos de interés, que se encargan de la planeación de las actividades turísticas en el área de estudio, desconocen información relevante que les permitiría conocer, identificarse, valorar y proponer acciones de conservación eficaces frente al reto de la sustentabilidad del ANP.

Considerando todo lo anterior, la utilidad de esta investigación versa en la generación de información que puede ser empleada para la creación de estrategias complementarias que contribuyan a acrecentar el nivel de sustentabilidad y las acciones de manejo en la zona estudio. No obstante, se considera relevante ampliar la muestra y número de agentes clave.

Finalmente, con base en la información generada las principales recomendaciones para mejorar el nivel de sustentabilidad del sitio son: 1) campañas de información para dar a conocer aspectos básicos relativos al plan de conservación de la zona; 2) organizar ferias y talleres de educación ambiental para dar a conocer al visitantes y a la población residente la importancia biológica de la zona; 3 ) estrechar lazos de colaboración en los diferentes sectores y mayor vinculación entre académicos, gobiernos, comunidad y empresa toda vez, que son actores que influyen en el éxito o fracaso de las medidas de conservación y manejo del sitio; 4) realizar estimaciones de capacidad de carga e implementar las medidas necesarias para que la zona sea visitada por el número de personas que, en forma estimada el ecosistema local sea capaz de soportar sin verse irreversiblemente afectado. 


\section{Referencias}

Arizpe, Oscar, et al. 2018, “Áreas Naturales Protegidas y turismo sustentable en Baja California Sur”, en: Juárez J. et al. (Coords.), Desarrollo Económico y Sustentabilidad en BCS, UAS, México.

Armenta Martínez, L. Propuesta de programa de manejo para la Reserva ecológica estatal Estero De San José, Tesis de maestría en ciencias marinas y costeras, Universidad Autónoma de Baja California Sur.

Ayuntamiento de Los Cabos, Baja California Sur 2016, "Primer informe de gobierno 2015-2016", en: http:// transparencialoscabos.gob.mx/documentos/transparencia/Articulo\%2070/Fraccion\%20XXIX/1er\%20 Informe/INFORME\%2022\%20Nov\%20FINAL.pdf

Barbier, E. et al. 1990, "Environmental Sustainability and Cost-Benefit Analysis", en: Environment and Planning, No.22, pp.1259-1266.

Barr, S. 2003, "Environmentalism in britain today. Who are environmentalists?", en: Town and Country Planning, August, pp. 185-186.

Bergh Van D. y Hofkes, M.1997, “A Survey of Economic Modeling of Sustainable Development”, TI Discussion Paper, 97/107, Tinbergen Institute, The Netherlands, Amsterdam-Rotterdam.

Bilsborrow, R., y Okoth-Ogendo, H. 1992, "Population-driven changes in land use in developing countries", en: Ambio (21), pp. 36-45.

Bojórquez Verástica, G. 2002, "Planificación de la actividad turística en el Complejo Insular del Espíritu Santo, Baja California Sur", Tesis de Maestría, Universidad Autónoma de Baja California Sur, La Paz, Baja California Sur.

Boletín Oficial Gobierno del Estado de Baja California Sur. 1994, Decreto que declara Reserva Ecológica Estatal, como área Natural protegida bajo la categoría de Zona sujeta a Conservación Ecológica, al denominado "Estero de San José del Cabo" ubicado en el Municipio de Los Cabos, Tomo XXI, Número 1.

Boletín Oficial Gobierno del Estado de Baja California Sur. 2010, Estudio diagnóstico de base de la Reserva Ecológica Estatal Estero de San José, Tomo XXXVII, Número 59 (extraordinario) 10 de diciembre de 2010.

Bones, M. et al. 2004, "Inhabitant's Environmental Perception in City of Rome within the Framework for Urban Biosphere Reserves of the UNESCO", Programme on Man and Biosphere, en: Annals of the New York Academy of Sciences, 1023, pp. 175-186.

Calderón, L. 2013, "Servicios ambientales de arrecifes coralinos: el caso de Cabo Pulmo, B.C.S.", en: ConCiencia, El Universal, en: http://blogs.eluniversal.com.mx/weblogs_detalle17890.html, fecha de consulta: 12 de septiembre de 2016.

Calero Vinelo, A. 1978, Técnicas de Muestreo, Editorial Pueblo y Educación, La Habana, pp. 514.

Cervantes Villegas, F. 2012, "Caracterización y diagnóstico ambiental del complejo insular espíritu santo, municipio de La Paz B.C.S", México, Tesis de licenciatura en Biología Marina, Universidad Autónoma de Baja California Sur, La Paz.

Cervantes-Martínez, E. 2013, "Propuesta de estrategia de turismo rural y de naturaleza en 12 comunidades de la REBIOSLA", en: Lagunas-Vázquez, M. (Coords.), en: Diagnóstico y análisis de los aspectos sociales y económicos en la Reserva de la Biosfera la Sierra la Laguna, Baja California Sur, México, Centro de Investigaciones Biológicas del Noroeste, México, pp. 89-116.

Clavé, S. 1998, "La urbanización turística. De la conquista del viaje a la reestructuración de la ciudad turística", Unidad de Geografía. Universitat Rovira i Virgili, Tarragona, España, en: Doc. Anal. Geogr. 32. http://ddd. uab.es/pub/dag/02121573n32p17.pdf. (Consultada: 06/12/2010).

Cohen, S. et al. 1998, "Climate change and sustainable development: towards dialogue", en: Global Environmental Change (8), pp. 341-371.

Common, M. y Perrings, C. 1992, "Towards an ecological economics of sustainability" en: Ecological economics, $\mathrm{N}^{\circ} 6$, pp. 7-34.

CONABIO 1997, Provincias biogeográficas de México, escala 1:4 000 000, México.

CONAGUA 2014, "Programa de medidas preventivas y de mitigación de la sequía", Comisión nacional del agua y Gobierno del estado de Baja California Sur.

CONANP 2006, "Programa de Turismo en Áreas Protegidas 2006-2012", Secretaría de Medio Ambiente y los Recursos Naturales, México, en: http://www.conanp.gob.mx/pdf_publicaciones/Turismopagsindividuales.pdf, 12 de septiembre de 2016.

CONANP 2016, “Áreas Naturales Protegidas Decretadas", en: https://www.gob.mx/conanp/acciones-yprogramas/areas-naturales-protegidas-decretadas, 12 de septiembre de 2017. 
CONANP-SEMARNAT 2000, "Programa de Manejo Complejo Insular del Espíritu Santo", Comisión Nacional de Áreas Naturales Protegidas-Secretaría de Medio Ambiente y Recursos Naturales, La Paz, B.C.S. México.

Córdova-Bojórquez, G. y Romo-Aguilar, M. 2017, "Participación ciudadana y ordenamiento ecológico local: el caso del municipio de Nogales, Sonora", en: Sociedad y Ambiente, (5) 14, pp. 31-52

Cortes, R. y Miranda, P. 2015, "Valoración económica de las actividades de buceo en El Parque Nacional Archipiélago Espíritu Santo", Tesis de Licenciatura, UABCS, México.

Daly, H. y Gayo, D. 1995, "Significado, conceptualización y procedimientos operativos del desarrollo sostenible: posibilidades de aplicación a la agricultura", en: Cadenas, A. (Ed.), Agricultura y desarrollo sostenible, Ministerio de Agricultura, Pesca y Alimentación, Madrid.

Dunlap, R. 1995, "Public opinion and environmental policy", en: Lester, J. P. (Ed.), Environmental Politics and Policy. Theories and Evidence, Duke Univ. Press, Durham, pp. 864-114.

Fasio, L. 2013, "Limitantes y Oportunidades del Desarrollo del Turismo de Naturaleza en Comunidades Rurales: El Caso de San Dionisio, Reserva de la Biosfera Sierra la Laguna, BCS, México", Tesis de Maestría, UABCS, México.

Fasio, L. e Ibáñez Pérez, R. 2011, "Problemática del Mercado Ecoturístico en la Reserva de la Biosfera Sierra La Laguna: el caso de San Dionisio, B.C.S.”, en: Teoría y Praxis, (10), pp. 49-75.

Fernández Moreno, Y. 2008, “¿Por qué estudiar las percepciones ambientales? Una revisión de la literatura mexicana con énfasis en Áreas Naturales Protegidas”, en: Espiral, Estudios sobre Estado y Sociedad Vol. $\mathrm{XV} \mathrm{N}^{\circ} 43$, pp. 179-202.

Ferrusquía-Villafranca, I. 1992, "Regionalización Biogeográfica IV.8.10. Atlas Nacional de México. Vol. II", escala 1: 4' 000, 000, Instituto de Geografía, UNAM, México.

Gobierno del Estado de Baja California Sur y SAGARPA. 2011, Diagnóstico sectorial del Estado de Baja California Sur. La Paz, B. C. S.

Gobierno del Estado de Baja California Sur. 2004, Programa de Manejo de la Reserva Ecológica Estatal „Estero de San José del Cabo, Secretaría de Planeación Urbana, Infraestructura y Ecología, La Paz.

González Pérez, G. et al. 2017, "Percepciones sociales sobre el mono araña (Ateles geoffroyi) e implicaciones para el emprendimiento de acciones de manejo y conservación en Oaxaca, México", en: Sociedad y Ambiente, (5) 14, pp. 53-73.

Hanley, N. 1997, Environmental Economics in the Theory and Practice, Oxford University Press, New York.

Hernández, V. 2013, Beneficios Económicos Derivados de la Creación del Parque Nacional Bahía de Loreto, en Opciones de gestión para recursos naturales en Baja California Sur, UABCS, México, pp.1-15.

Hernández Sampieri, R. 2014, Metodología de la investigación, Editorial Mc Graw-Hill, 6ta edición.

Ibáñez, R. 2014, “Turismo y sustentabilidad en pequeñas localidades costeras de Baja California Sur", en: El Periplo Sustentable, 26, pp. 71-105.

Ibáñez, R. 2015, "Caracterización y problemática socioambiental del desarrollo turístico en San José del Cabo, Baja California Sur”, en: Barragán, F. y M., Maldonado (Coords.), El turismo y el desarrollo comunitario. Investigaciones y propuestas, Universidad de Querétaro, pp. 145-174.

Ibáñez, R. et al. 2016, "Perfil y satisfacción del visitante del destino: Los Cabos, Baja California Sur", en: Revista Opción, Año 32, Especial No.13, Venezuela, pp. 1041-1068.

Ibáñez, R. 2016, "Barómetro de sustentabilidad para sitios turísticos de Baja California Sur (BCS)", en: Denarius: Revista de Economía: Nueva época. No.31, pp. 191-229.

INE-SEMARNAT-UABCS-CIB-CICIMAR-CICESE-CONACYT-Gobierno del Estado de BCS 2012, Plan de Acción ante el Cambio Climático para Baja California Sur.

INEGI 2015, Encuesta intercensal 2015, Instituto Nacional de Estadística y Geografía, en: http://www3.inegi. org. $\mathrm{mx} / \mathrm{rnm} /$ index.php/catalog/214

INEGI. 2010, "Censo de Población y Vivienda 2010. Instituto Nacional de Estadística y Geografía", en: http:// www.inegi.org.mx/sistemas/olap/proyectos/bd/consulta.asp?p=17118\&c $=27769 \& \mathrm{~s}=$ est $[8$ de Julio de 2014].

Jamieson, D. 1998, "Sustainability and beyond", en: Ecological Economics, N.24, pp.183-192.

Kettunen, M. 2010, "Recognising the value of protected areas (in the economics of ecosystems and biodiversity (TEEB) report for policy-makers)", Conference, Nature Conservation beyond 2010, May 27-29, 2010 Tallin, Estonia, en: http://ph.emu.ee/ conference100/Abstracts/Abstract_Kettunen_2.pdf (consultado el 26 septiembre 2012) 
Lezama, J. 2008, La construcción social y política del medio ambiente, El Colegio de México, México.

López, Á. y Sánchez, Á 2002, "Canales Espaciales de Distribución en el Corredor Turístico Los Cabos, Baja California Sur, México", en: Cuadernos de Turismo, №9, pp 53-66.

Martínez, J. et al. 2013, "Bienestar socioeconómico y percepción de la calidad de vida en destinos turísticos: el caso de la colonia el Caribe, Cabo San Lucas, Baja California Sur (México)", en: Tur y Des, Vol 6, № 15.

Moyano, E. et al. 2009, "Políticas ambientales, cambio climático y opinión púbica en escenarios regionales. El caso de Andalucía", en: Revista internacional de sociología, Septiembre-Diciembre, vol. 67, (3), pp. 681-699.

Mulongoy, K. y Chape, S. 2004, Protected areas and biodiversity. An overview of key issues, Nairobi, UNEPWCMC Biodiversity Series No. 21. United Nations Environment Programme, Kenya.

Novo, M. 2002. "Globalización, cambio de paradigma y educación ambiental”, en: Novo, M. (Dir.), Globalización, crisis ambiental y educación, Aulas de Verano, ISFP, MEC.

Pearce, D. y Atkinson, G. 1995, "Measuring sustainable development", Chapter 8 en The Handbook of environmental economics, en: D.W. Bromley, Oxford, UK, Blackwell.

Olmos-Martínez E. 2015,"Servicios ecosistémicos con potencial turístico del parque nacional Archipiélago espíritu Santo, México", en: Teoría y praxis, pp.158-173.

Olmos-Martínez, E. 2013a, "Análisis de la percepción de las comunidades sobre el Decreto de Área Natural Protegida reserva de la biosfera Sierra La Laguna, B.C.S”, en: Lagunas-Vázques M. et al. (Eds.). Diagnóstico y análisis de los aspectos sociales y económicos en la reserva de la biosfera Sierra La Laguna, Baja California Sur, México. La Paz, B.C.S., Centro de Investigaciones Biológicas del Noroeste S.C., México, pp. 257-274.

Olmos-Martínez, E. et al. 2013b, "Percepción de la población frente al cambio climático en áreas naturales protegidas de Baja California Sur, México", en: Polis (35), en: http://polis.revues.org/9158; DOI: 10.4000/ polis.9158, (consultado el 15 octubre 2013).

Olmos-Martínez, E. 2016, “Opinión pública y percepción sobre la conservación de la Reserva Ecológica Estatal Estero San José del Cabo y su zona de influencia”, en: Revista de Comunicación Vivat Academia. Año XIX $\mathrm{N}^{\circ}$ 135. pp. $24-40$.

Ponce Sánchez, M. 2004, "Percepción del modelo turístico de Sol y Playa. El caso del Mar Menor", en: Papeles de Geografia, Escuela de Turismo de Murcia (39), en: http://www.um.es/dp-geografia/papeles/n39/09PERCEPCION.pdf. (consultado el 09/01/2011), pp.173-186

Rebolledo, R. 2013, "Más de mil visitantes espera la Sierra de La Laguna en Semana Santa", en: Diario el Peninsular, en: http://peninsulardigital.com/bcs-2/mas-de-mil-visitantes-espera-la-sierra-de-la-laguna-ensemana-santa/109785, (consultado 14 de septiembre de 2016).

Retamal, R. et al. 2011, "Percepción al cambio climático y a la gestión del agua: aportes de las estrategias metodológicas cualitativas para su comprensión”, en: Ambiente \&Sociedad, Campinas V. XIV. N. 1, pp. 175-194.

Robles-Camacho, M. 2018, "Vulnerabilidad socioeconómica ante el cambio climático", en: Villerías Salinas, S. (Coord.), en: Análisis de la vulnerabilidad social desde un enfoque multidisciplinario, Universidad Autónoma de Guerrero, México.

SAGARPA - Gobierno del estado de Baja California Sur. 2011, Diagnóstico sectorial del Estado de Baja California Sur. La Paz, B. C. S.

Santander, L. 2005, "Desarrollo y turismo sustentable: Paradigmas, ideología y práctica social", en: Frausto, O. (Coord.), Desarrollo sustentable: turismo, costas y educación, Universidad de Quintana Roo, Cozumel.

SEMARNAT 2013, "Número de visitantes en áreas autorizadas para la actividad de observación de Ballena en Baja California Sur, 2010-2011 y 2011-2012", en: Informes de Gobierno de BCS, México.

SEMARNAT-CONANP 2014, "Programa Nacional de Áreas Naturales Protegidas 2014-2018”, Plan Nacional de Desarrollo 2013-2018, en: http://www.conanp.gob.mx/datos_abiertos/DES/PNANP2014-2018.pdf

Solow, R. 1993, "An almost practical step toward sustainability”, en: Resources Policy, N 19, pp.162-172.

Tudela Serrano, M. 2008, "Capacidad de Carga Turística en Cuatro Senderos de Caravaca de la Cruz (Murcia)", en: Revista electrónica de medio ambiente, $\mathrm{N}^{\circ}$ 6, pp.1-20.

UNFPA. 1991, "La población, los recursos y el medio ambiente", Los desafios críticos, Fondo de Población de las Naciones Unidas. 